\title{
Correlative Analysis of Ion Concentration Profile and Surface Nanoscale Topography Changes using Operando Scanning Ion Conductance Microscopy
}

\begin{abstract}
Yasufumi Takahashi*[a, b, c, d], Daiko Takamatsu ${ }^{[\mathrm{e}]}$, Yur
Abstract: Although various spectroscopic methods have been developed to capture the ion concentration profile changes, it is still difficult to visualize the ion concentration profile and surface topographical changes simultaneously during the charging/discharging of LIBs. To tackle this issue, we have developed an operando scanning ion-conductance microscopy (SICM) method that can directly visualize an ion concentration profile and surface topography using a SICM nanopipette whilst controlling sample potential or current by potentiostat for characterizing the polarization state during charging/discharging. Using operando SICM on the negative electrode (anode) of LIBs, we have characterized ion concentration profile changes and the reversible volume changes related to the phase transition during cyclic voltammetry $(\mathrm{CV})$ and charge/discharge of the hard carbon anode. Operando SICM is a versatile technique that is likely to be of major value for evaluating correlation of the electrolyte concentration profile and nanoscale surface topography changes.
\end{abstract}

The electrochemical reactions and topography changes of lithiumion secondary batteries (LIBs) involve non-equilibrium and multi-step phenomena such as $\mathrm{Li}^{+}$ion transport, $\mathrm{Li}^{+}$-solvation/desolvation, $\mathrm{Li}^{+}$ intercalation, structural changes of cathode/anode, formation and deposition of by-products, and expansion of cathode/anode. Capturing such multi-step and time-dependent changes with a relevant spatiotemporal resolution enables optimizing the operating conditions and cathode/separator/anode structure and identifying the additives for proper solid-electrolyte interphase (SEI) formation taking into account non-equilibrium changes.

Currently, several methods have been used to monitor the ion concentration profile, including in situ nuclear magnetic resonance $(\mathrm{NMR})^{[1]}$, magnetic resonance imaging $(\mathrm{MRI})^{[2]}$, neutron scattering ${ }^{[3]}$,

[a] Prof. Y. Takahashi, Prof.Y. E. Korchev, Prof. T. Fukuma WPI Nano Life Science Institute (NanoLSI, WPI) Kanazawa University Kakuma-machi, Kanazawa, Ishikawa 920-1192 (Japan) E-mail: yasufumi@se.knazawa-u.ac.jp

[b] Prof. Y. Takahashi, Prof. T. Fukuma

Division of Electrical Engineering and Computer Science, Kanazawa University, Kakuma-machi, Kanazawa, 920-1192, Japan

[c] Prof. Y. Takahashi

Department of Electronics, Graduate School of Engineering, Nagoya University, Nagoya 464-8603, Japan

[d] Prof. Y. Takahashi

Precursory Research for Embryonic Science and Technology (PRESTO)

Japan Science and Technology Agency (JST)

Saitama, 332-0012 (Japan)

[e] Dr. Daiko Takamatsu

Center for Exploratory Research, Research \& Development Group, Hitachi, Ltd., Hatoyama-machi, Saitama 350-0395, Japan

[f] Prof.Y. E. Korchev

Department of Medicine, Imperial College London, London W12 ONN, United Kingdom

Supporting information for this article is given via a link at the end of the document. i E. Korchev ${ }^{[a, f]}$, Takeshi Fukuma ${ }^{[a, b]}$

$X$-ray imaging ${ }^{[4]}$, and Raman microscopy ${ }^{[5]}$. In situ surface-sensitive $\mathrm{X}$-ray absorption spectroscopy has been clarified that Co reduction at the $\mathrm{LiCoO}_{2}$ surface resulting from electrolyte contact causes initial degradation. ${ }^{[6]}$ Scanning transmission X-ray microscopy has been developed to probe the spatiotemporal evolution of Li composition and intercalation rate within primary particles ${ }^{[7]}$ Electron beam irradiation and electron energy-loss spectroscopy have been used to sense the Li-intercalation reactions in the local region..$^{[8]}$ The volume change of the hard carbon anode has been estimated by X-Ray diffraction ${ }^{[4 d]}$, neutron diffraction, ${ }^{[9]}$ and neutron transmission Bragg-edge imaging ${ }^{[10]}$. However, most analytical tools are difficult to perform the correlative analysis of topographical changes and ion concentration profile during charging/discharging because of the difference in the measurement conditions and scale limitations of each analytical tool.

Scanning probe microscopy (SPM), which uses a tiny probe for sensing the sample surface properties with topographic imaging, has been used for such correlative analysis. Conductive atomic force microscopy (c-AFM) can visualize conductance changes and topographical changes simultaneously. ${ }^{[11]}$ The double-layer structure of two ionic liquids has also been directly probed using AFM. ${ }^{[12]}$ Electrochemical strain microscopy can visualize surface topography and Li diffusion. ${ }^{[13]}$ Scanning electrochemical microscopy (SECM) can visualize the SEI formation. ${ }^{[14]}$ Scanning electrochemical cell microscopy (SECCM), which uses a nanopipette capable of acting as a micro battery cell, can visualize the surface reactivity of cathode and anode material at a sub-micrometer resolution. ${ }^{[15]}$ SECCM can be easily performed for high-resolution electrochemical imaging because a meniscus-shaped electrochemical cell forms on the sample surface via a nanopipette. However, SECCM cannot visualize the vertical chemical distribution and structural changes (such as the formation of dendrites) because the whole sample does not immerse in the solution. Such ion concentration profile changes derived from the whole LIB's reaction are still a critical issue for imaging by SPMs.

Scanning ion conductance microscopy (SICM), which uses a nanopipette as a probe, is a promising technology to visualize the ion concentration profile with sub microscale. SICM is known as a noncontact topographic imaging technique in solution because ion current is used as feedback for probe-sample distance control. ${ }^{[16]}$ This feature of noncontact topographic imaging in solution is effective for live-cell time-lapse imaging. ${ }^{[16 d, 17]}$ For convoluted sample imaging, hopping mode and similar techniques have been developed to avoid nanopipette-sample contact. ${ }^{[16 c, 18]}$ The hopping mode involves approaching and withdrawing the nanopipette at all measurement points. Hersam and coworkers have used SICM for LIBs analysis. ${ }^{[19]}$ The local ion current measurement using a nanopipette was effective not only for topographic imaging but also for monitoring local ion transport via ion channels, ${ }^{[20]}$ tight junctions, ${ }^{[21]} 3 \mathrm{D}$ ion distribution, ${ }^{[22]}$ permeability, ${ }^{[23]}$ ionic reactions, ${ }^{[24]}$ and surface charge. ${ }^{[25]}$ Local ion delivery is also attractive application for SICM. ${ }^{[26]}$ However, SICM has been used principally for live cell measurements. Simultaneous 
potential and current control of SICM and LIBs material have been difficult for conventional SICM.

Nanopipette-based electrochemical measurement is effective for characterizing the local ion concentration. The first nanopipette-based electrochemical measurement was reported by Bard and coworkers. ${ }^{[27]}$ They observed the nonlinear potential-current response which is called the rectification effect, when they used a tiny quartz nanopipette for cyclic voltammetry (CV) measurement. The relationship between the electrolyte concentration gradient and rectification was also reported. ${ }^{[28]}$ Siwy and coworkers investigated $\mathrm{Li}^{+}$ transfer using $\mathrm{LiClO}_{4}$ as an electrolyte for the model of $\mathrm{LIBs}^{\left[{ }^{[29]}\right.}$

In this work, we have developed an operando SICM system for directly visualizing ion concentration profile and nanoscale topographic changes at an anode surface during the CV and charge/discharge characteristic. We have characterized the composite electrode of the hard carbon anode and the flat model electrode of highly oriented pyrolytic graphite (HOPG) by using operando SICM. To perform the operando measurement by SICM, we have developed hardware and software that can independently control the potential of the LIB's electrode and SICM working electrode by using a potentiostat and the current amplifier, respectively. We have also constructed a characterization technique for a three-dimensional ion concentration profile. These enable operando measurement by SICM on the surface of the electricity storage material. a
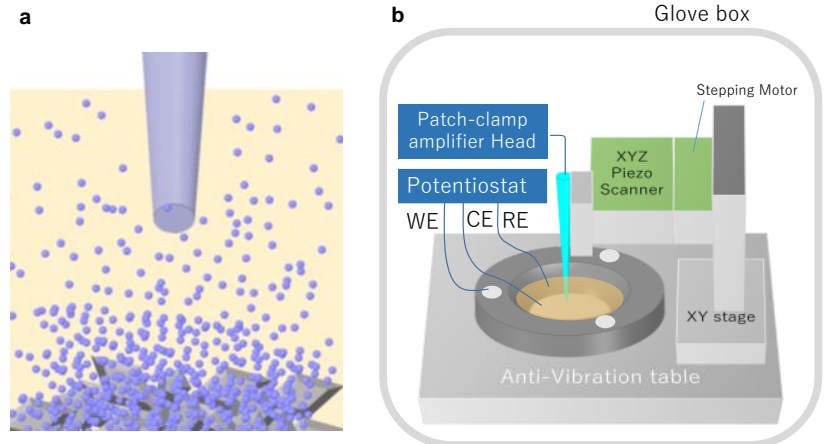

Figure 1. Scheme of the operando SICM. a Scheme of an ion concentration measurement using nanopipette. b System diagram of operando SICM. The potential of the sample and SICM Li metal wire electrode were controlled by the potentiostat and patch-clamp current amplifier, respectively. To perform the operando measurement, the potential of the potentiostat and current amplifier was synchronized to keep constant the potential of the current amplifier during the electrochemical measurement. The whole system was placed in a glove box to keep the low oxygen and dew point temperature.
SICM nanopipette brought close to the sample surface using ion current distance control (Fig.1). During the CV of the sample, the nanopipette position was kept at $10 \mu \mathrm{m}$ distance from the sample surface and applied $+0.7 \mathrm{~V}$ (vs. $\mathrm{Li} / \mathrm{Li}^{+}$; all voltages in this paper quoted as vs. $\left.\mathrm{Li}^{\prime} \mathrm{Li}^{+}\right)$. SICM's ion current feedback-based distance control required a high temporal resolution current measurement greater than $1 \mathrm{kHz}$ with $\mathrm{nA}$ current level. Therefore, we used a patch-clamp amplifier instead of a bipotentiostat. The detail of the electric circuit is described in the supporting information (Fig. S1). To investigate the relationship between the SICM ion current response and corresponding salt concentration, we changed the $\mathrm{LiClO}_{4}$ concentration and characterized the SICM ion current by $\mathrm{CV}$ measurement. To eliminate the solution resistance-related $i R$ drop for characterizing the $\mathrm{LiCiO}_{4}$ concentration and ion current relationship we used a double-barreled nanopipette (Fig2a). During this experiment, we kept the nanopipette $\mathrm{LiClO}_{4}$ concentration to $1.0 \mathrm{M}$. Figure $\mathbf{2 b}$ shows the scanning electron microscopy image of the double-barreled nanopipette and CV curves obtained at various $\mathrm{LiClO}_{4}$ concentrations on the outside of the nanopipette. The size of the nanopipette aperture radius was $30 \mathrm{~nm}$. In this experiment, we used a two-electrode system and performed the measurement outside of the glovebox. The $\mathrm{Ag} / \mathrm{AgCl}$ wires ${ }^{[30]}$ were inserted into both barrels and connected working and reference/counter electrodes, respectively. The nanopipette was held at an adequate distance from the substrate for measurement. Figure $2 \mathbf{c}, \mathbf{d}$ show the $\mathrm{CV}$ curves and ion current responses at $+0.7 \mathrm{~V}$ of the different $\mathrm{LiClO}_{4}$ concentrations. We observed the linear relationship between the electrolyte concentration and ion current. We also characterized the single nanopipette fabrication reproducibility, stability of the ion current drift during the long-time measurement, and aperture size and I-V response relationship and confirmed the reliability of the current detection using the single nanopipette (Fig. S2, S3). These results mean that the SICM nanopipette can be used to monitor the electrolyte concentration change in battery materials.

\section{Results and Discussion}

To monitor the ion concentration change on the sample surface during CV or charge/discharge, we used a half-cell system for controlling the sample potential or current by a potentiostat and a 

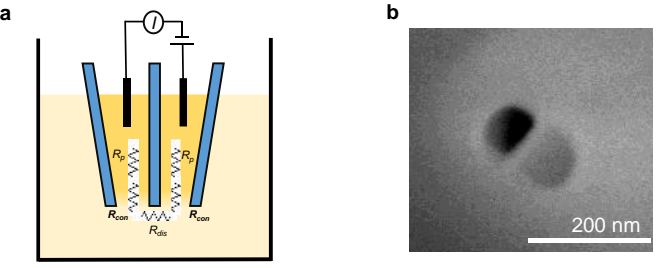

d


Figure 2. Characterization of the relationship of the ion current and $\mathrm{LiClO}_{4}$ concentration. a Scheme of an ion concentration measurement using double barrelled nanopipette. The solution resistance is defined as $R_{\text {sol }}=R_{\text {con }}+R_{\text {dis. }}$. $R_{\text {con }}$ is the nanopipette around electrolyte concentration-dependent resistance. $R_{\text {dis }}$ is the distance-dependent solution resistance between nanopipette and reference. To eliminate the effect of $R_{\text {dis }}$ related $i R$ drop, the double-barrelled nanopipette was used. b Scanning electron microscopy image of double-barrelled nanopipette, c Typical CVs of the double-barrelled nanopipette with $1.0 \mathrm{M} \mathrm{LiClO}_{4}$ in $\mathrm{EC} / \mathrm{DEC}=1 / 2(\mathrm{v} / \mathrm{v})$ inside nanopipette and varied $\mathrm{LiClO}_{4}$ concentrations outside nanopipette. $d$ The calibration plot of $\mathrm{LiClO}_{4}$ concentration and ion current signal at the $0.7 \mathrm{~V}$.

For characterizing the electrolyte concentration profile change by operando SICM, we measured the SICM current with different distances between the single nanopipette and the hard carbon anode during $\mathrm{CV}$ of the hard carbon anode. The potential range of $\mathrm{CV}$ was 0 to $1.7 \mathrm{~V}$. During the $\mathrm{CV}$, the $50 \mathrm{~nm}$ radius $\mathrm{SICM}$ single nanopipette potential was kept at $+0.7 \mathrm{~V}$. The distance between the nanopipette and the hard carbon anode was maintained at 10, 100, 1000, 3000 $\mu \mathrm{m}$, and the CV scan rate were $10 \mathrm{mV} / \mathrm{s}$. Figure $3 \mathbf{a}, \mathbf{b}$ shows the nanopipette-sample distance-dependent SICM current changes during the $\mathrm{CV}$ measurement of the hard carbon anode. The current responses of the hard carbon anode and the SICM were contrasting. This is due to the inhomogeneous distribution of the counter ion caused by the intercalation and (de)intercalation of $\mathrm{Li}^{+}$near the hard carbon anode surface, and the current response of SICM depends on the concentration of the counter ion. Ion transport in an electrolyte solution in the presence of an applied electric field occurs as a combination of migration and diffusion. For example, during the charging of the hard carbon anode (i.e. $\mathrm{Li}^{+}$insertion to the carbon), the electric field causes the migration of cations (i.e. $\mathrm{Li}^{+}$) to the negative electrode (i.e. hard carbon anode) and anions (i.e. $\mathrm{ClO}_{4}{ }^{-}$) toward the positive electrode (i.e. counter electrode $\mathrm{CE}$ ). While $\mathrm{Li}^{+}$ ions recombine at the hard carbon anode with the electrons that passed through the outer circuit, $\mathrm{ClO}_{4}^{-}$ions do not react with the electrode, and instead accumulate in the vicinity of the CE. Consequently, the concentration of cations also increases near the CE to maintain the local electroneutrality of the electrolyte solution. This leads to the formation of an ion concentration gradient in the electrolyte solution and to a diffusion flux opposing it. Therefore, the current change of SICM became smaller when the samplenanopipette distance increased even if the hard carbon anode current responses were the same. We also characterized the sample
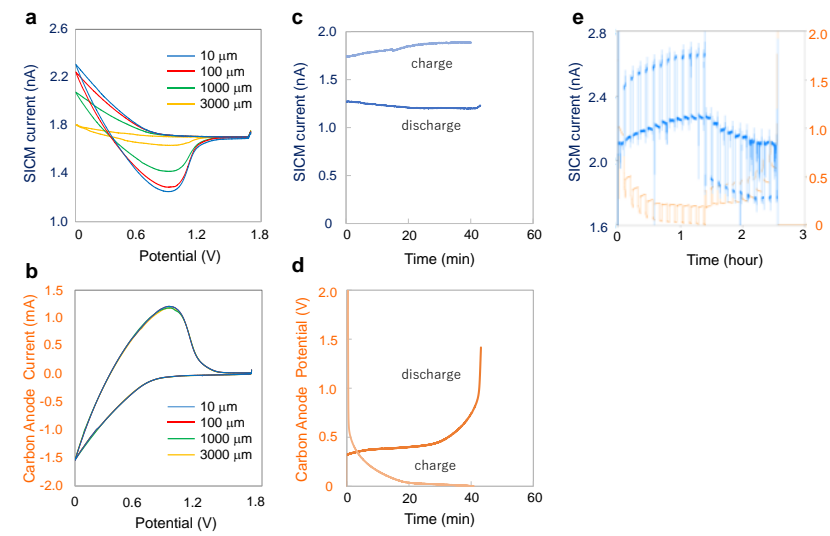

Time (hour)

Figure 3. Ion concentration monitoring using operando SICM. a SICM and b hard carbon anode currents during $\mathrm{CV}$ of the hard carbon anode on different nanopipette-sample distances. Scan rates were $10 \mathrm{mV} / \mathrm{s}$. c SICM current and $\mathrm{d}$ hard carbon anode potential during the charging/discharging characteristic. The current density of hard carbon was $0.4 \mathrm{~mA} / \mathrm{cm}^{2}$. e GITT of the hard carbon anode and SICM current measurement. The $0.8 \mathrm{~mA} / \mathrm{cm}^{2}$ pulse current was applied $120 \mathrm{~s}$. Rest time was $300 \mathrm{~s}$. During the SICM ion current measurement, the potential of the nanopipette was kept at $0.7 \mathrm{~V} \mathrm{vs.} \mathrm{Li}^{2} \mathrm{Li}^{+}$and the nanopipette of SICM kept $10 \mu \mathrm{m}$ distance from the sample surface. The nanopipettes radii were $50 \mathrm{~nm}$ and filled with $1.0 \mathrm{M} \mathrm{LiClO}_{4}$ in $\mathrm{EC} / \mathrm{DEC}=1 /$ $2(\mathrm{v} / \mathrm{v})$.

potential scan rate-dependent ion concentration change using SICM and conformed the contrasted response of SICM current to the hard carbon anode's Li intercalation/(de)intercalation current (Fig. S4)). These results mean that the Operando SICM is thus useful to detect transient ion concentration profile changes.

Ion concentration profile detection during charge/discharge characteristics was also capable of being assessed by operando SICM. In this experiment, the single nanopipette position was kept at $10 \mu \mathrm{m}$ distance from the sample surface and had an applied potential of $+0.7 \mathrm{~V}$. Figure $3 \mathbf{c}, \mathbf{d}$ shows the charge/discharge curve of the hard carbon anode whilst controlling the applying current at $0.4 \mathrm{~mA} / \mathrm{cm}^{2}$. Change in SICM's current corresponding to the ion concentration change was observed in both the charging and discharging processes. Notably, unlike the case of CV, the ion current increased or decreased at an almost constant rate regardless of the change in the potential on the hard carbon anode. In charging/discharging at a low rate, the ion concentration profile had to be in a steady state because of the balance of ion migration and diffusion. On the other hand, in $\mathrm{CV}$ with a fast scan rate, the change in SICM current was considered to be large because the electric field is constantly changing and the ion migration and diffusion are in constant conflict and imbalance.

The SICM current interacts with the electrochemical potential of the sample surface. To distinguish the effect of the chemical potential and electrochemical potential, we performed galvanostatic intermittent titration technique (GITT) for hard carbon anode and measured ion current simultaneously using SICM. We observed the SICM ion current changes when switching the constant current $\left(0.8 \mathrm{~mA} / \mathrm{cm}^{2}\right)$ to open circuit potential (OCP). The SICM current responses were related to electrochemical potential and chemical potential, 
a

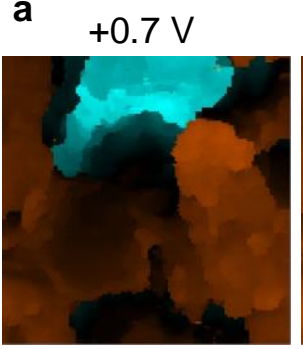

$+0.1 \mathrm{~V}$



C

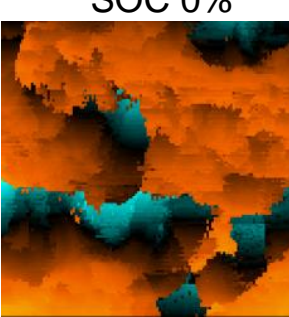

$+0.5 \mathrm{~V}$

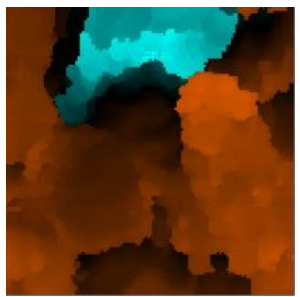

$+0.2 \mathrm{~V}$

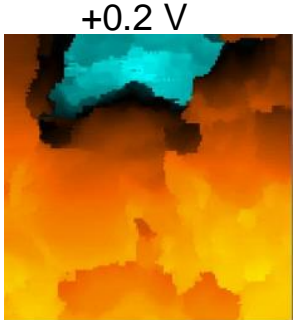

SOC $100 \%$

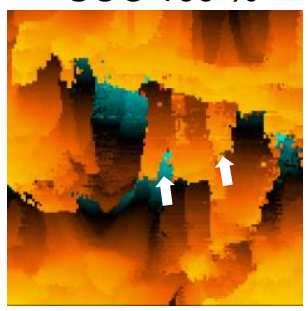

$+0.3 \mathrm{~V}$



$+0.3 \mathrm{~V}$

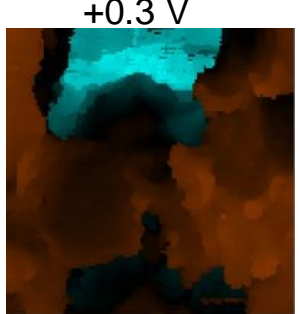

SOC $0 \%$

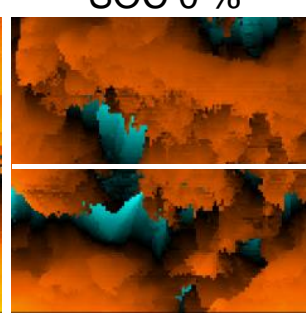

b

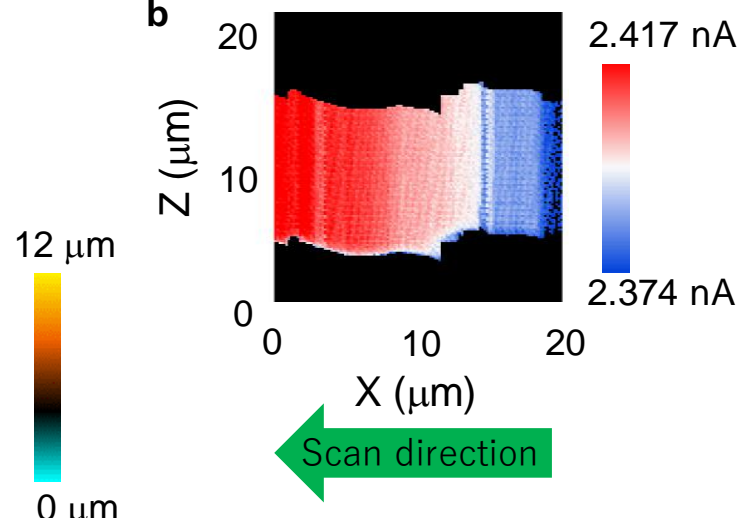

$0 \mu \mathrm{m}$

d
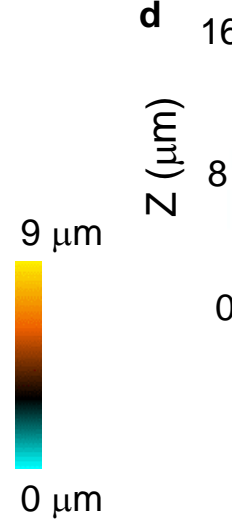

8

0

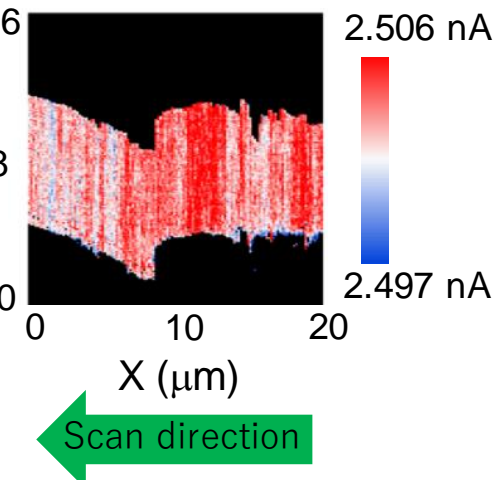

Figure 4. SICM topography and ion profile imaging of the hard carbon anode. a Time-lapse SICM topography images of the hard carbon anode with step potential sweep. Before the imaging, the rest period was set at $5 \mathrm{~min}$ to suppress the double layer capacitance current. During the SICM imaging, the hard carbon potential was kept constant. The image was acquired by applying the constant voltage of $0.7 \mathrm{~V} \mathrm{vs.} \mathrm{Li/Li+.} \mathrm{b} \mathrm{XZ} \mathrm{SICM} \mathrm{ion} \mathrm{current} \mathrm{image,} \mathrm{where} \mathrm{the}$ image point is shown on the white line indicated in Fig. 4a. c SICM topography images of before (SOC $0 \%$ ) and after charging (SOC $100 \%$ ), discharging (SOC $0 \%)$ hard carbon anode. During the SICM imaging, the hard carbon current was kept constant (0 mA). The SICM image was acquired by applying the constant voltage of $0.8 \mathrm{~V}$ vs. $\mathrm{Li} / \mathrm{Li}+$ to an SICM Li electrode. $\mathrm{d}$ XZ SICM ion current image, where the image point is shown on the white line indicated in Fig. 4c. Scan size and pixel numbers of a and b were $20 \times 20 \mu \mathrm{m}^{2}$ and $128 \times 128$, respectively. The nanopipettes radii were $50 \mathrm{~nm}$ and filled with $1.0 \mathrm{M}$ LiClO 4 in EC / DEC $=1 / 2(\mathrm{v} / \mathrm{v})$.

respectively. The SICM current change before and after the pulse current to the hard carbon anode was $0.35 \mathrm{nA}$, which was constant regardless of the carbon SOC. In addition, during the OCP of the hard carbon, a change in hard carbon potential was observed, but no significant change was observed in the SICM current. It is thought that the concentration gradient formed during the charging/discharging can be kept constant by setting the hard carbon anode current as 0 $\mathrm{mA}$. This result means the electrolyte concentration profile can be measured as a SICM current and electrochemical potential and chemical potential can be distinguished by GITT.

To confirm the surface topographic changes of the hard carbon during charging/discharging, the potential of the hard carbon was changed by $200 \mathrm{mV}$ steps from 1.7 to $0.1 \mathrm{~V}$ and from $0.2 \mathrm{~V}$ to $1.6 \mathrm{~V}$ imaged by SICM. During the imaging, the $50 \mathrm{~nm}$ radius SICM single nanopipette potential was kept at $+0.7 \mathrm{~V}$. Before the SICM measurement, we set a 5 minutes rest period to suppress the double layer capacitance current, which is induced by the potential step. Figure 4 shows the time-lapse of SICM images of the hard carbon anode obtained by changing the potential. The SICM topographic image of hard carbon of the stacked polyhedral flake plates with dimensions of 3-4 $\mu \mathrm{m}$ was in good agreement with the scanning electron microscopy image (Fig. S5). The hopping mode scanning algorithm and SICM noncontact distance control feature are effective in capturing the topographic image of the convoluted structure of the hard carbon anode. From $1.7 \mathrm{~V}$ to $0.9 \mathrm{~V}$, we could not observe the clear topographic changes. From 0.9 to $0.1 \mathrm{~V}$, we found the volume expansion related to the phase transition. Notably, the structural change was observed in the image of $0.2 \mathrm{~V}$. The green arrow shows the detachment region of the hard carbon polyhedral flake plate. We also observed shrinkage of the structure from 0.2 to $1.6 \mathrm{~V}$. We then reconstructed the SICM ion current signal during the imaging and characterized the microscale ion current profile as images (Fig.4b). SICM current is affected by the current flow of the carbon electrode. Thus, it is difficult to visualize the electrolyte distribution. To capture the ion concentration profile, the sample needs to be controlled as OCP.

To characterize the surface topographic changes and ion concentration profile after charging and discharging of the hard 
a Single point measurement

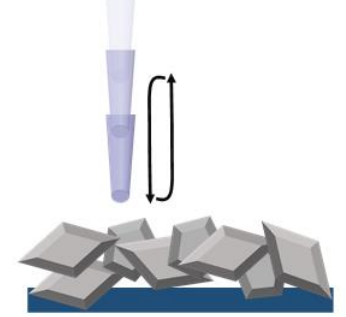

c One line scanning

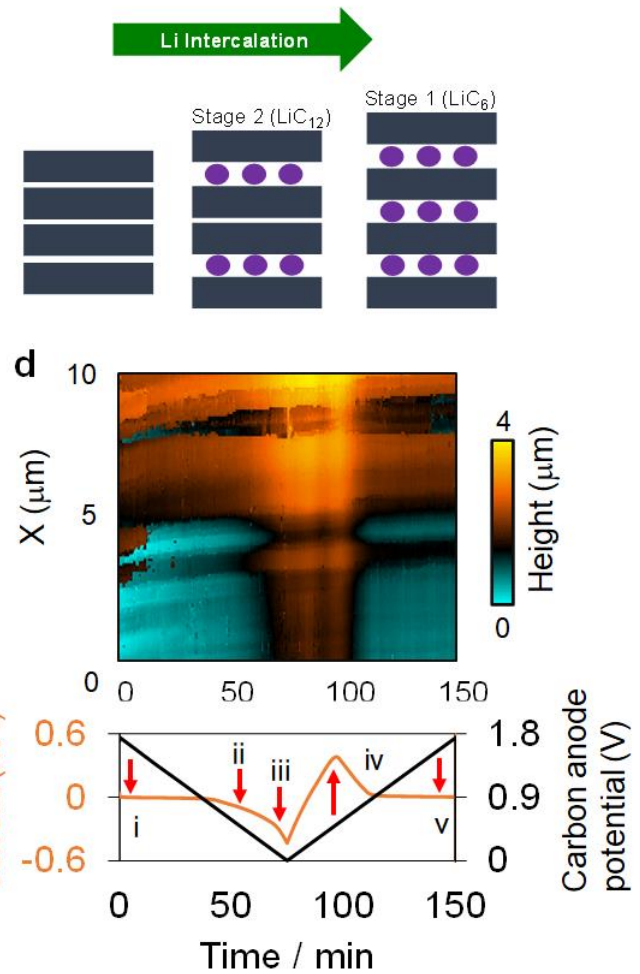

b
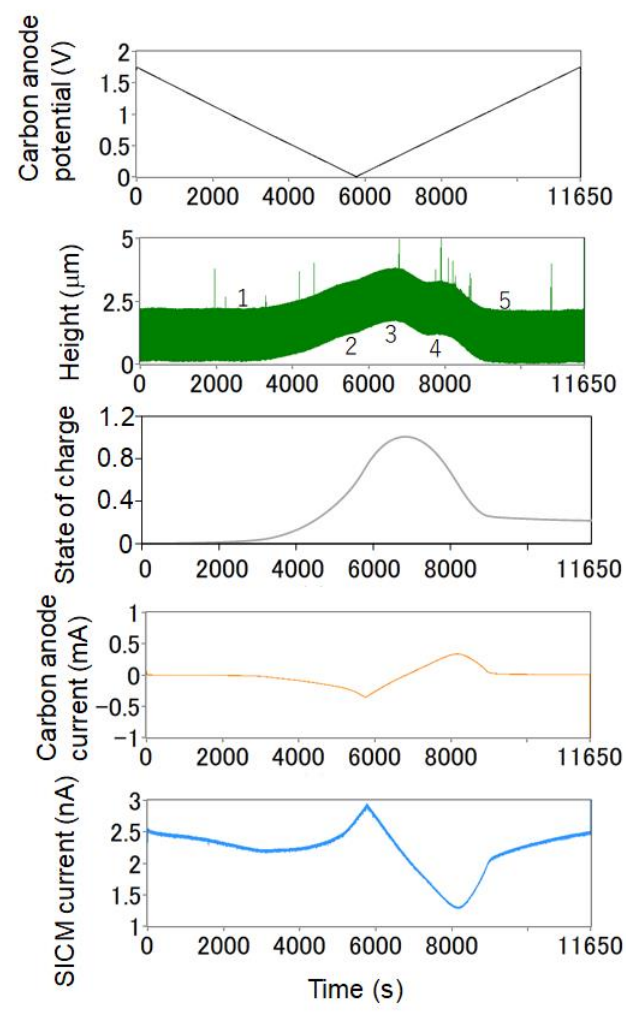

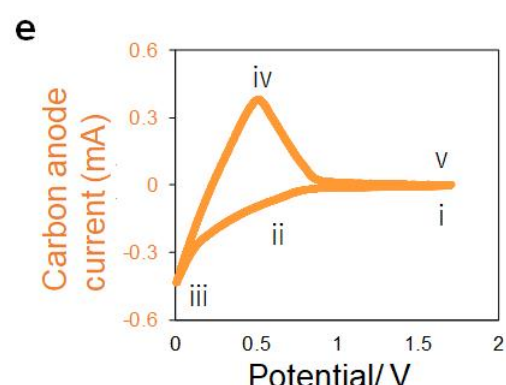

Potential/ V

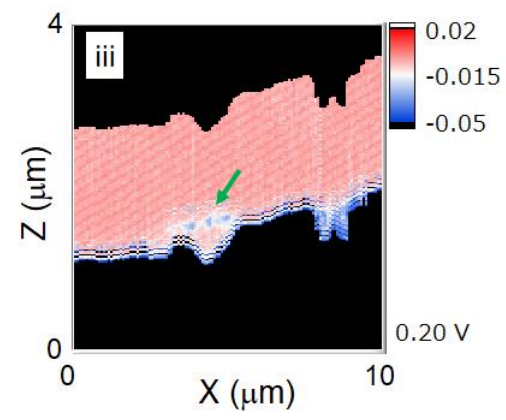

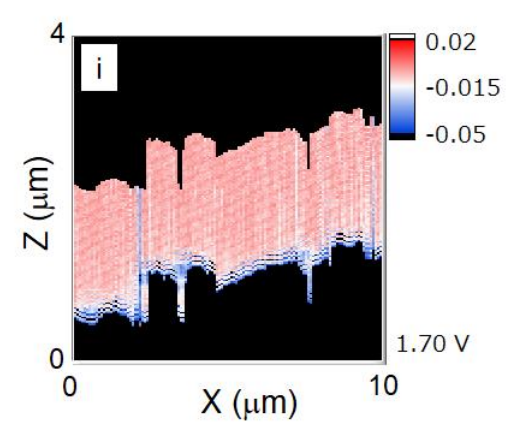

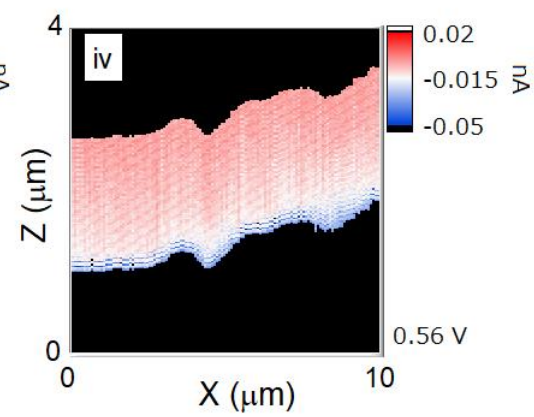

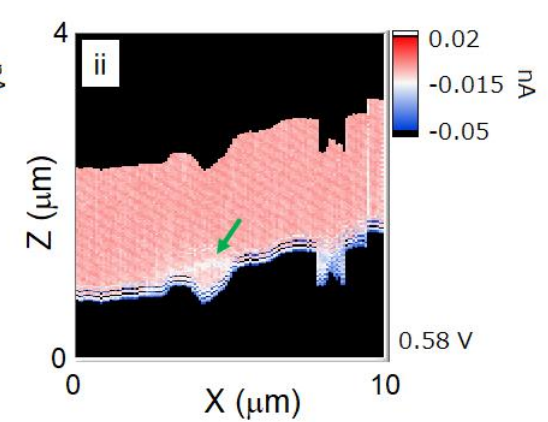

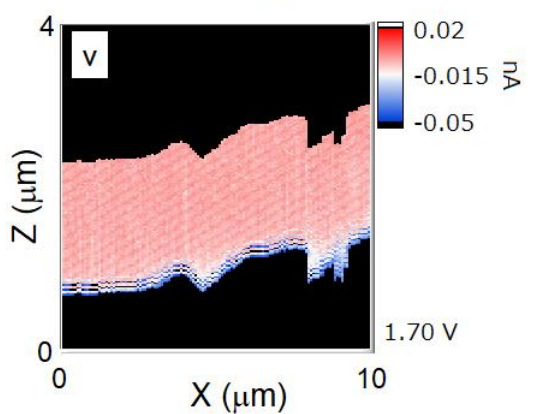

Figure 5. Volume change monitoring during the $\mathrm{CV}$ of the hard carbon anode by Operando SICM. a Scheme of the single point measurement. $\mathrm{b}$ Time course of the potential, height, state of charge, carbon anode current, and SICM current during the CV. c Scheme of the continuous one-line scanning measurement. $\mathrm{d}$ Time course of the one-line height image, carbon anode current, and SICM current during the $\mathrm{CV}$. The sweep rate was $0.3 \mathrm{mV} / \mathrm{s}$. e SICM ion current $\mathrm{XZ}$ images, where the image points are shown in Fig. 5d. Hopping amplitude and the falling rate of SICM were $2000 \mathrm{~nm}$ and $30 \mathrm{~nm} / \mathrm{ms}$, respectively. The nanopipettes radii were $50 \mathrm{~nm}$ and filled with $1.0 \mathrm{M} \mathrm{LiClO}_{4}$ in $\mathrm{EC} / \mathrm{DEC}=1 / 2(\mathrm{v} / \mathrm{v})$. The height monitoring was acquired by applying the constant voltage of 0.7 V vs. $\mathrm{Li} / \mathrm{Li}^{+}$. 
a



b

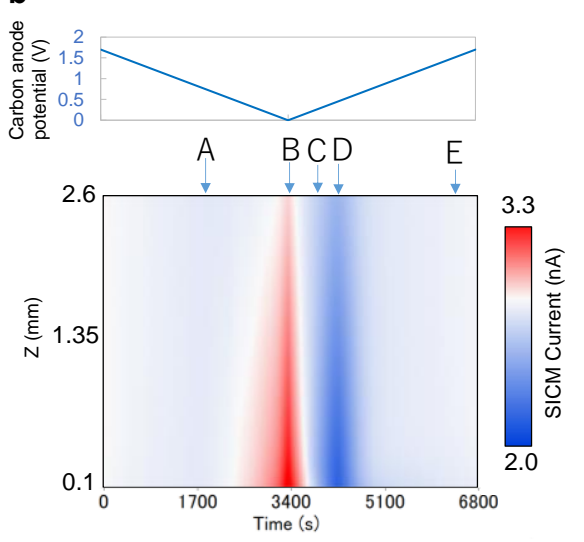

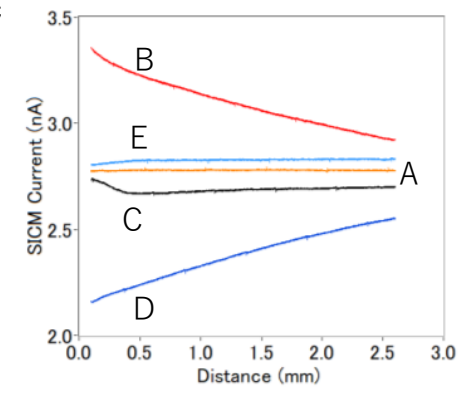

Figure 6. Millimeter-scale ion concentration profile monitoring during the CV of hard carbon anode by Operando SICM. a Time course signals and SICM currents during the CV. The SICM current responses with the nanopipette-sample distance of $0.1 \mathrm{~mm}, 1.35 \mathrm{~mm}$, and $2.6 \mathrm{~mm}$ were picked up and showed as a blue, red, and green line, respectively. b Time course image of SICM height and ion current during the CV. c Approach curves at the point of A-E of (a,b). The sweep rate was $0.5 \mathrm{mV} / \mathrm{s}$. Hopping amplitude and the falling/withdrawing rate of the nanopipette were $2.5 \mathrm{~mm}$ and $0.5 \mathrm{~mm} / \mathrm{s}$, respectively. The nanopipettes radii were 50 $\mathrm{nm}$ and filled with $1.0 \mathrm{M} \mathrm{LiClO}_{4}$ in $\mathrm{EC} / \mathrm{DEC}=1 / 2(\mathrm{v} / \mathrm{v})$. The SICM ion current was acquired by applying the constant voltage of $0.7 \mathrm{~V}$ vs. $\mathrm{Li}^{2} \mathrm{Li}{ }^{+}$

the hard carbon's topography. During the imaging, the $50 \mathrm{~nm}$ radius SICM single nanopipette potential was kept at $+0.8 \mathrm{~V}$. Figure $4 \mathrm{c}$ shows the result. Firstly, the hard carbon anode was discharged to $1.7 \mathrm{~V}$ of the current density with $0.4 \mathrm{~mA} / \mathrm{cm}^{2}$ (i.e. state of charge (SOC) was $0 \%$ ). Undulating hard carbon topography was visualized by hopping mode SICM. Then, the hard carbon anode was charged to 0 $\checkmark$ of the current density with $0.4 \mathrm{~mA} / \mathrm{cm}^{2}$ (i.e. SOC was $100 \%$ ) and kept at open circuit potential to image the topography by SICM. The white arrow areas show the huge structurally changed regions. These changes seemed to stretch the pillar. To control the sample potential as an open circuit potential was effective to visualize the topographic changes before and after charging. Finally, we discharged the hard carbon anode again (SOC was $0 \%$ ). Some structural changes returned to their original state because of the phase transition, but a part of the structure did not. It is thought that the irreversible structural changes are related to age-associated deterioration. We then characterized the SICM ion current signal during the imaging as $X Z$ images (Fig.4d). The XZ SICM current image was almost uniform. This result means that the electrolyte diffusion is fast enough in the micrometer-scale region of the electrode surface, and observing the concentration profile requires millimeter-scale measurement.

To evaluate the spatial resolution of the SICM, we characterized HOPG by SECCM. In this experiment, commercial HOPG (NT-MDT GRBS/0.6) was used for SECCM imaging. During the imaging, the 50 $\mathrm{nm}$ radius SICM single nanopipette potential was kept at $+0.8 \mathrm{~V}$. To find the step edge, we measured the topographic image after several times charging/discharging cycled HOPG (Fig. S6a). The step edge was clearly visualized. We averaged height at the red square region to estimate the step edge height (Fig. S6b). The step edge height was $10 \mathrm{~nm}$. The step edge swellings were reported as being formed by decomposition products of cointercalated solvent molecules between graphite layers beneath the surface. This is in keeping with the previous report. ${ }^{[31]}$ These results mean that the SICM spatial resolution is beyond that of optical microscopy.
It is known that the $\mathrm{Li}$ intercalation into carbon is accompanied by a stage like change in the average layer between carbon planes (phase transition) as a function of $\mathrm{Li}$ contents (SOC). ${ }^{[32]}$ To estimate the volume change of the hard carbon during $\mathrm{CV}$ in real-time, we were not able to set the rest period. Therefore, we monitored sample height continuously at the single point on the carbon anode by hopping the SICM's single nanopipette. To save the height estimation artifact of interference of electrolyte concentration change dependent SICM current change, the setpoint was $98 \%$ ( $2 \%$ decrease from the reference current), a significantly large value for SICM distance control. Hopping amplitude and falling rates were $2000 \mathrm{~nm}$ and 30 $\mathrm{nm} / \mathrm{ms}$, respectively. CV sweep rate of the hard carbon anode was $0.3 \mathrm{mV} / \mathrm{s}$. In this experiment, a $50 \mathrm{~nm}$ radius single nanopipette was used. Figure 5 a shows a schematic of the single-point height change monitoring during the CV of the hard carbon anode by SICM. Figure 5 b shows the time course of the potential, height, carbon anode current, and SICM current during the CV. To characterize the effect of ion current change during the CV for nanopipette-sample control, we analyzed the maximum ion current change during ten continuous hopping processes. The ion current change of the process was $0.5 \%$. This value is relatively small in relation to the setpoint. Therefore, under these experimental conditions, we could avoid an artifact in height measurement due to changes in ion concentration. During the $\mathrm{CV}$, the phase transition-related hard carbon anode volume change was observed from $+0.8 \mathrm{~V}$ (Fig. 5b, Point 1)). This volume expansion was continued until the $50 \%$ SOC. (Fig. 5 b, Point 2). This volume change corresponded with the phase transition from stage $1 \mathrm{~L}-4 \mathrm{~L}-3 \mathrm{~L}-$ $2 \mathrm{~L}$ to stage ${ }^{\left[{ }^{[4 d]}\right.}$ The volume then expanded again until the SOC reached $100 \%$. This volume change corresponded to the phase transition from stage 2 to stage 1 (Fig.5 b Point 4). The volume shrinkage corresponding with the phase transition from stage 1 to stage 2 was observed until the $50 \%$ SOC. In the same manner, stage 2 to $1 \mathrm{~L}-4 \mathrm{~L}-3 \mathrm{~L}-2 \mathrm{~L}$ stage was also observed (Fig. 5 b Point 5). The volume expansion was estimated from the height change and thickness of the hard anode carbon $(28 \mu \mathrm{m})$. The volume changes of stage $1 \mathrm{~L}-4 \mathrm{~L}-3 \mathrm{~L}-$ $2 \mathrm{~L}$ to stage 2 and stage 2 to stage 1 were $4.11 \%(1.15 \mu \mathrm{m})$ and $1.78 \%$ $(0.50 \mu \mathrm{m})$, respectively. The total volume change was $5.89 \%$. We 
also performed time-lapse one-line scanning for visualizing the volume change during the charge/discharge (Fig.5d). The vertical axis shows the $\mathrm{X}$ position of the one-line scan, the horizontal axis shows the time course, and the color contrast shows the sample height. The reversible volume change-related phase transition was clearly visualized by SICM. We then reconstructed the SICM ion current signal during the time-lapse imaging and characterized the microscale ion current profile as images. In most cases, the transient ion current change caused by the potential change of the hard carbon anode was dominant. To remove this transient ion current change effect, we normalized the ion current signal of $X Z$ images by evaluating ion current difference from the mode value at each of the approaching curves. This processing is effective to remove the transient ion current changes and easy to visualize the ion current gradient. We observed a low ion current region around the depressed structure during the $\mathrm{CV}$ (Fig. 5e, green arrows and Supporting Movies1). We also found the 250 - $300 \mathrm{~nm}$ region near the electrode where the ion current decreases. These results suggest that operando SICM is an effective tool for characterizing such micrometer-scale height and electrolyte profile changes during charging/discharging.

A millimeter-scale ion concentration profile can also be monitored by operando SICM. The nanopipette position was controlled by a stepping motor and the measurement range and velocity were $2.5 \mathrm{~mm}$ and $0.5 \mathrm{~mm} / \mathrm{s}$. In this experiment, a $50 \mathrm{~nm}$ radius single nanopipette was used. The nanopipette-hard carbon distance was controlled from $0.1 \mathrm{~mm}$ to $2.6 \mathrm{~mm}$. CV sweep rate was $0.5 \mathrm{mV} / \mathrm{s}$. Figure 6 a shows the time-course of the signals of the hard carbon anode and SICM current during the $\mathrm{CV}$. Figure $\mathbf{6 b}$ shows the time-course image of the nanopipette-sample distance and SICM ion current during the CV. Figure $6 \mathbf{c}$ shows the approach characteristic at the point of A-E of Fig $6 a$. The time-course image of the SICM current is easy to understand as the counter ion profile was changed during $\mathrm{CV}$ as a millimeterscale. During the forward scan, the SICM's current change was not observed until $0.8 \mathrm{~V}$ (Fig. 6c Point A). The SICM's current was then increased when the nanopipette was close to the sample because of the increase of the counter ion concentration at the hard carbon surface (Fig. 6c, Point B). This trend was changed at $+0.5 \mathrm{~V}$ of the reverse scan (Fig. 6c, point $\mathrm{C}$ ). The polarized counter ion distribution was observed only within $0.4 \mathrm{~mm}$ from the sample surface. This is because counter ion concentration decreased due to the applied potential to the hard carbon anode. The SICM current response decreased when the nanopipette was close to the sample because the counter ion moved to the counter electrode surface (Fig. 6c, Point $D)$. At the end of the $\mathrm{CV}$, the counter ion concentration profile was almost uniform (Fig.6c, Point E). From these results, we conclude that operando SICM is also useful to monitor the millimeter-scale ion profile change with sample charging/discharging current responses during the $\mathrm{CV}$ of the sample.

\section{Conclusion}

In this study, we have established operando SICM for correlative analysis of the ion concentration change and nanoscale topography change of LIBs's electrolyte solution during charging and discharging. We first characterized the relationship between $\mathrm{Li}^{+}$ concentration and SICM ion current. We then visualized the topographic changes and characterized the local ion current changes during charge/discharge and CV using operando SICM. Notably, we observed reversible phase transition-related volume change during the CV measurement of the hard carbon electrode. Reversible and irreversible topographic changes and milli-meter scale ion concentration profiles were also visualized clearly by SICM. The spatial resolution of SICM is beyond the optical limit and this enabled us to visualize the step edges of HOPG. Operando SICM has the potential to unveil the LIBs non-equilibrium mechanism and bottleneck processes such as dendrite formation by correlative analysis of the dendrite formation and the ion concentration for optimizing the separator structure.

\section{Experimental Section}

\section{Operando SICM setup.}

The details of the SICM setup have been reported in our previous work. ${ }^{[16 \mathrm{~d}]}$ The glass nanopipettes (aperture inner radius, $50 \mathrm{~nm}$ ) were fabricated from borosilicate glass capillaries (GC100F-15, Harvard Apparatus) using a $\mathrm{CO}_{2}$ laser puller (Model P-2000, Sutter Instruments). The SICM uses a nanopipette probe containing a $1 \mathrm{M}$ $\mathrm{LiClO}_{4}$ in a 1:2 volumetric mixture of ethylene carbonate (EC) and diethylene carbonate (DEC). $\mathrm{Li}$ metal was intercalated into the nanopipette and used as the SICM working electrode.

For the operando SICM measurement, sample potential, or current control during SICM current detection is essential. The potential and current of the sample LIB materials were controlled by a potentiostat (TM-3000, EC Frontier) and a homemade Labview program. Li metal was used for reference and counter electrodes. The surface area of the sample was $0.50 \mathrm{~cm}^{2}$. The potentials of SICM working and LIB material working electrodes were controlled individually. The reference electrode was shared by the potentiostat and the current amplifier. The potential between the potentiostat working electrode and the current amplifier working electrode was controlled using the external bias input function of the current amplifier and Labview program. The detail of the electric circuit is described in the supporting information (Figure S1).

\section{Sample preparation.}

The hard carbon anodes were composed of a mixture of 97 wt\% graphite active material, 1 wt\% carboxymethyl cellulose (CMC), and $2 \mathrm{wt} \%$ styrene-butadiene rubber (SBR) binder. The slurry was coated onto a copper current collector (thickness: $10 \mu \mathrm{m}$ ), which was used as the negative electrode. The coating amount of the negative electrode layer, density, and thickness were $10.2 \mathrm{mg} \mathrm{cm}^{-2}, 1.56 \mathrm{~g}$ $\mathrm{cm}^{-3}$, and $28 \mu \mathrm{m}$, respectively (Fig. S5).

\section{Acknowledgment}

A Grant-in-Aid for Scientific Research (A) (19H00915), a Grantin-Aid for Young Scientists (A) (15H05422), a Grant-in-Aid for 
Exploratory Research (15K13263 and 20K21141), and Grant-in-Aid for Scientific Research on Innovative Areas (16H00885) from the Japan Society for the Promotion of Science (JSPS), World Premier International Research Center Initiative (WPI), MEXT, Japan, and Asahi Glass Foundation, Grant-in-Aid for Young Scientists provided by Hokuriku bank, Murata Science Foundation, and Toyota Mobility Foundation (TMF) are all thankfully acknowledged for financial support.

Keywords: Scanning ion conductance microscopy • ion profile imaging $\cdot$ correlative imaging

[1] a) M. Klett, M. Giesecke, A. Nyman, F. Hallberg, R. W Lindström, G. Lindbergh, I. Furó, J Am Chem Soc 2012, 134, $14654-14657$; b) S. A. Krachkovskiy, A. D. Pauric, I. C. Halalay, G. R. Goward, The Journal of Physical Chemistry Letters 2013 4, 3940-3944; c) K. Hayamizu, S. Seki, H. Miyashiro, Y. Kobayashi, The Journal of Physical Chemistry B 2006, 110, 22302-22305; d) S. A. Krachkovskiy, J. M. Foster, J. D. Bazak, B. J. Balcom, G. R. Goward, The Journal of Physical Chemistry C 2018, 122, 21784-21791.

[2] a) H. J. Chang, A. J. Ilott, N. M. Trease, M. Mohammadi, A. Jerschow, C. P. Grey, J Am Chem Soc 2015, 137, 15209-15216; b) S. A. Krachkovskiy, J. D. Bazak, P. Werhun, B. J. Balcom, I. C. Halalay, G. R. Goward, J Am Chem Soc 2016, 138, 7992-7999; c) J. D. Bazak, S. A. Krachkovskiy, G. R. Goward, The Journal of Physical Chemistry C 2017, 121, 20704-20713.

[3] C. J. Jafta, X.-G. Sun, G. M. Veith, G. V. Jensen, S. M. Mahurin M. P. Paranthaman, S. Dai, C. A. Bridges, Energ Environ Sci 2019, 12, 1866-1877.

[4] a) D. Takamatsu, A. Yoneyama, Y. Asari, T. Hirano, J Am Chem Soc 2018, 140, 1608-1611; b) J. I. G. Dawkins, M. Z. Ghavidel, D. Chhin, I. Beaulieu, M. S. Hossain, R. Feng, J. Mauzeroll, S. B. Schougaard, Analytical Chemistry 2020, 92, 10908-10912; c) M J. Mühlbauer, D. Petz, V. Baran, O. Dolotko, M. Hofmann, R. Kostecki, A. Senyshyn, J Power Sources 2020, 475, 228690; d) S. Schweidler, L. de Biasi, A. Schiele, P. Hartmann, T. Brezesinski, J. Janek, The Journal of Physical Chemistry C 2018, 122, 8829-8835.

[5] a) J. D. Forster, S. J. Harris, J. J. Urban, The Journal of Physical Chemistry Letters 2014, 5, 2007-2011; b) Z. Wei, A. Salehi, G. Lin, J. Hu, X. Jin, E. Agar, F. Liu, J Power Sources 2020, 449, 227361; c) Q. Cheng, L. Wei, Z. Liu, N. Ni, Z. Sang, B. Zhu, W. $\mathrm{Xu}$, M. Chen, Y. Miao, L.-Q. Chen, W. Min, Y. Yang, Nat Cоттип 2018, 9, 2942.

[6] a) D. Takamatsu, T. Nakatsutsumi, S. Mori, Y. Orikasa, M. Mogi, H. Yamashige, K. Sato, T. Fujimoto, Y. Takanashi, H. Murayama, M. Oishi, H. Tanida, T. Uruga, H. Arai, Y. Uchimoto, Z. Ogumi, Journal of Physical Chemistry Letters 2011, 2, 2511-2514; b) D. Takamatsu, Y. Koyama, Y. Orikasa, S. Mori, T. Nakatsutsumi, T. Hirano, H. Tanida, H. Arai, Y. Uchimoto, Z. Ogumi, Angewandte Chemie-International Edition 2012, 51, 11597-11601.

[7] J. Lim, Y. Y. Li, D. H. Alsem, H. So, S. C. Lee, P. Bai, D. A. Cogswell, X. Z. Liu, N. Jin, Y. S. Yu, N. J. Salmon, D. A. Shapiro, M. Z. Bazant, T. Tyliszczak, W. C. Chueh, Science 2016, 353, 566-571.

[8] M. Kitta, M. Kohyama, Phys Chem Chem Phys 2017, 19, 1158111587.

[9] C. Didier, W. K. Pang, Z. Guo, S. Schmid, V. K. Peterson, Chem Mater 2020, 32, 2518-2531.

[10] T. Kamiyama, Y. Narita, H. Sato, M. Ohnuma, Y. Kiyanagi, Physics Procedia 2017, 88, 27-33.

[11] M. G. Verde, L. Baggetto, N. Balke, G. M. Veith, J. K. Seo, Z. Wang, Y. S. Meng, Acs Nano 2016, 10, 4312-4321.

[12] R. Hayes, N. Borisenko, M. K. Tam, P. C. Howlett, F. Endres, R. Atkin, The Journal of Physical Chemistry C 2011, 115, 68556863.
[13] a) N. Balke, S. Jesse, Y. Kim, L. Adamczyk, A. Tselev, I. N. Ivanov, N. J. Dudney, S. V. Kalinin, Nano Lett 2010, 10, 34203425 ; b) N. Balke, S. Jesse, A. N. Morozovska, E. Eliseev, D. W Chung, Y. Kim, L. Adamczyk, R. E. García, N. Dudney, S. V. Kalinin, Nat Nanotechnol 2010, 5, 749-754; c) S. Jesse, N. Balke, E. Eliseev, A. Tselev, N. J. Dudney, A. N. Morozovska, S. V. Kalinin, ACS Nano 2011, 5, 9682-9695.

[14] a) G. Zampardi, E. Ventosa, F. La Mantia, W. Schuhmann, Chem Commun 2013, 49, 9347-9349; b) E. Ventosa, G. Zampardi, C. Flox, F. La Mantia, W. Schuhmann, J. R. Morante, Chem Commun 2015, 51, 14973-14976; c) G. Zampardi, F. La Mantia, W. Schuhmann, $R s c A d v$ 2015, 5, 31166-31171; d) J. S. Hui, M. Burgess, J. R. Zhang, J. Rodriguez-Lopez, Acs Nano 2016, 10, 4248-4257.

[15] a) Y. Takahashi, A. Kumatani, H. Munakata, H. Inomata, K. Ito, K. Ino, H. Shiku, P. R. Unwin, Y. E. Korchev, K. Kanamura, T. Matsue, Nat Commun 2014, 5, 5450; b) H. Inomata, Y. Takahashi, D. Takamatsu, A. Kumatani, H. Ida, H. Shiku, T. Matsue, Chem Commun 2019, 55, 545-548; c) B. Tao, L. C. Yule, E. Daviddi, C. L. Bentley, P. R. Unwin, Angewandte Chemie International Edition 2019, 58, 4606-4611; d) M. E. Snowden, M. Dayeh, N. A. Payne, S. Gervais, J. Mauzeroll, S. B. Schougaard, J Power Sources 2016, 325, 682-689; e) M. Dayeh, M. R. Z. Ghavidel, J. Mauzeroll, S. B. Schougaard, Chemelectrochem 2019, 6, 195 201; f) Y. Takahashi, T. Yamashita, D. Takamatsu, A. Kumatani, T. Fukuma, Chem Commun 2020, 56, 9324-9327.

[16] a) C. Zhu, K. Huang, N. P. Siepser, L. A. Baker, Chem Rev 2020; b) Y. E. Korchev, C. L. Bashford, M. Milovanovic, I. Vodyanoy, M. J. Lab, Biophys J 1997, 73, 653-658; c) P. Novak, C. Li, A. I Shevchuk, R. Stepanyan, M. Caldwell, S. Hughes, T. G. Smart, J. Gorelik, V. P. Ostanin, M. J. Lab, G. W. J. Moss, G. I. Frolenkov, D. Klenerman, Y. E. Korchev, Nat Methods 2009, 6, 279-281; d) Y. Takahashi, Y. Zhou, T. Miyamoto, H. Higashi, N. Nakamichi, Y. Takeda, Y. Kato, Y. Korchev, T. Fukuma, Analytical Chemistry 2020, 92, 2159-2167.

[17] a) H. Ida, Y. Takahashi, A. Kumatani, H. Shiku, T. Matsue, Anal Chem 2017, 89, 6016-6021; b) S. Simeonov, T. E. Schaffer, Nanoscale 2019, 11, 8579-8587.

[18] Y. Takahashi, Y. Murakami, K. Nagamine, H. Shiku, S. Aoyagi, T. Yasukawa, M. Kanzaki, T. Matsue, Phys Chem Chem Phys 2010, 12, 10012-10017.

[19] A. L. Lipson, R. S. Ginder, M. C. Hersam, Adv Mater 2011, 23 5613-5617.

[20] a) P. Novak, J. Gorelik, U. Vivekananda, A. I. Shevchuk, Y. S. Ermolyuk, R. J. Bailey, A. J. Bushby, G. W. J. Moss, D. A Rusakov, D. Klenerman, D. M. Kullmann, K. E. Volynski, Y. E Korchev, Neuron 2013, 79, 1067-1077; b) W. Shi, Y. Zeng, C. Zhu, Y. Xiao, T. R. Cummins, J. Hou, L. A. Baker, Small 2018 14,1702945 .

[21] a) L. Zhou, Y. Gong, J. Hou, L. A. Baker, Analytical Chemistry 2017, 89, 13603-13609; b) K. Huang, L. Zhou, K. Alanis, J. Hou, L. A. Baker, Chem Sci 2020, 11, 1307-1315.

[22] a) Y. Takahashi, H. Ida, Y. Matsumae, H. Komaki, Y. S. Zhou, A. Kumatani, M. Kanzaki, H. Shiku, T. Matsue, Phys Chem Chem Phys 2017, 19, 26728-26733; b) K. Cremin, B. A. Jones, J. Teahan, G. N. Meloni, D. Perry, C. Zerfass, M. Asally, O. S. Soyer, P. R. Unwin, Analytical Chemistry 2020, 92, 16024-16032. [23] N. A. Payne, J. I. G. Dawkins, S. B. Schougaard, J. Mauzeroll, Analytical Chemistry 2019, 91, 15718-15725.

[24] B. Liu, Y. Shao, M. V. Mirkin, Anal Chem 2000, 72, 510-519.

[25] a) K. McKelvey, S. L. Kinnear, D. Perry, D. Momotenko, P. R Unwin, $J$ Am Chem Soc 2014, 136, 13735-13744; b) L. H. Klausen, T. Fuhs, M. Dong, Nat Commun 2016, 7, 12447; c) A Page, D. Perry, P. Young, D. Mitchell, B. G. Frenguelli, P. R. Unwin, Analytical Chemistry 2016, 88, 10854-10859.

[26] a) J. Teahan, D. Perry, B. Chen, I. J. McPherson, G. N. Meloni, P. R. Unwin, Analytical Chemistry 2021, 93, 12281-12288; b) B. Babakinejad, P. Jonsson, A. L. Cordoba, P. Actis, P. Novak, Y Takahashi, A. Shevchuk, U. Anand, P. Anand, A. Drews, A Ferrer-Montiel, D. Klenerman, Y. E. Korchev, Analytical Chemistry 2013, 85, 9333-9342; c) J. D. Piper, R. W. Clarke, Y 
E. Korchev, L. M. Ying, D. Klenerman, J Am Chem Soc 2006, $128,16462-16463$.

[27] C. Wei, A. J. Bard, S. W. Feldberg, Analytical Chemistry 1997, 69, 4627-4633.

[28] a) L.-J. Cheng, L. J. Guo, Nano Lett 2007, 7, 3165-3171; b) X. L. Deng, T. Takami, J. W. Son, E. J. Kang, T. Kawai, B. H. Park, Sci Rep-Uk 2014, 4, 4005.

[29] T. Plett, W. Shi, Y. Zeng, W. Mann, I. Vlassiouk, L. A. Baker, Z S. Siwy, Nanoscale 2015, 7, 19080-19091.

[30] C. L. Bentley, D. Perry, P. R. Unwin, Analytical Chemistry 2018, 90, 7700-7707.

[31] a) S.-K. Jeong, M. Inaba, T. Abe, Z. Ogumi, J Electrochem Soc 2001, 148, A989; b) S.-K. Jeong, M. Inaba, Y. Iriyama, T. Abe, Z. Ogumi, Electrochim Acta 2002, 47, 1975-1982; c) Z. Zhang, K. Smith, R. Jervis, P. R. Shearing, T. S. Miller, D. J. L. Brett, Acs Appl Mater Inter 2020, 12, 35132-35141.

[32] J. R. Dahn, Phys Rev B 1991, 44, 9170-9177. 
